EDITORIAL

\title{
Contribuições singulares em tempos de incertezas
}

Alvaro Chrispino ${ }^{a}$

Há dois anos, em 31 de dezembro de 2019, a OMS (Organização Mundial de Saúde) emitia o primeiro alerta de doença identificada na cidade de Wuhan (China) e que se transformou na Pandemia causada pelo SAR-CoV-2 (Covid-19), cujos impactos nefastos e os números não precisam ser indicados por serem de domínio público. Entretanto, para compor nosso argumento, precisamos lembrar que a Pandemia da Covid-19 levou ao necessário isolamento social, dando margem ao surgimento de movimentos sociais anti-vacina e negacionistas da ciência, dificultando a implementação de ações baseadas em evidências da ciência e da tecnologia.

Os impactos na economia são sentidos até hoje e o desemprego, que já estava em patamar preocupante, atinge parte importante da população economicamente ativa e retira também as possibilidades dos milhões de informais e subempregados de manterem condições mínimas de subsistência. Como consequência, em síntese, a fome e a insegurança alimentar se instalam e são mensuradas em recente pesquisa intitulada Inquérito Nacional sobre Insegurança Alimentar no Contexto da Pandemia da Covid-19 no Brasil, realizada pela Rede Brasileira de Pesquisa em Soberania e Segurança Alimentar e Nutricional (Rede Penssan), onde encontramos a informação que dá mostra da gravidade do problema: "Do total de 211,7 milhões de brasileiros(as), 116,8 milhões conviviam com algum grau de Insegurança Alimentar e, desses, 43,4 milhões não tinham alimentos em quantidade suficiente e 19 milhões de brasileiros(as) enfrentavam a fome" (REDE PENSSAM, 2021). Esse fato, por si só, já impacta de forma importante toda a rede de garantia de direitos e de proteção social brasileira.

No que concerne à Educação, em 31 de maio de 2020, quase 1 bilhão e 600 milhões estudantes de 193 países estavam com aulas suspensas em escolas e em universidades, o que representava $91,3 \%$ de todas as matrículas do mundo 1 . Até os dias atuais, os sistemas de ensino, como um todo, ainda não retornaram às aulas de forma regular considerando dificuldades de variadas ordens. Ao longo desses dois anos, os sistemas de ensino foram chamados a buscar alternativas

\footnotetext{
Centro Federal de Educação Tecnológica Celso Suckow da Fonseca, Rio de Janeiro, RJ, Brasil

Estimativas diárias promovidas pela UNESCO disponíveis em: https://pt.unesco.org/covid19/educationresponse
} 
metodológicas para superarem os problemas para os quais não estavam preparados, usando ferramentas até então não disponibilizadas para as ações corriqueiras de gestores, professores, alunos e comunidade. Escolas de diferentes matizes ofereceram alternativas singulares de acordo com suas possibilidades, sendo certo que alunos de escolas públicas, de baixo poder aquisitivo e do sexo feminino (WORLD BANK, 2021), de forma geral, não foram alcançados de forma satisfatória por programas de atendimento educacional, ampliando as dificuldades de aprendizagens já conhecidas. Oportuno relembrar as reflexões de Gomes et al. (2021) sobre a Educação e os tempos atuais:

As perdas tendem a ser gerais, porém, os menos favorecidos foram os mais prejudicados. Cumpre não repetir os erros nem restaurar o passado sem mudanças, pois as circunstâncias são outras. Além do déficit de aprendizagem, é preciso recuperar a Educação em suas diversas finalidades. Para tanto, cabe apoiar educadoras.es, estudantes e famílias, enfocando os menos privilegiados, com a participação das forças vivas da comunidade e da sociedade (p. 2).

São inúmeros os estudos que exploram e mapeiam essas dificuldades no presente e no futuro. Dentre tantos, podemos escolher a pesquisa conduzida por Barros et al. (2021) que simula a Perda de Aprendizagem na Pandemia, e extrair que

os estudantes que concluíram a $2^{\mathrm{a}}$ série do ensino médio em 2020 iniciaram a $3^{\mathrm{a}}$ série com uma proficiência (em língua portuguesa e matemática) entre 9 e 10 pontos [pontos da escala Saeb-Sistema de Avaliação da Educação Básica] abaixo do que iriam alcançar caso não tivessem tido a necessidade de transitar do ensino presencial para o ensino remoto devido à pandemia.

E complementam sobre as perdas indicadas para 2021:

caso, ao longo do ano letivo de 2021, o ensino remoto seja mantido e não ocorra um aumento no grau de engajamento dos estudantes, as perdas deverão alcançar níveis quase duas vezes mais elevados: 16 em língua portuguesa a 20 pontos em matemática.

Ao indicar perdas de aprendizagem, o estudo traz à baila a questão histórica das desigualdades que se ampliaram nos tempos de pandemia. Os estudantes, que tinham pouco, até isso perderam. 
Temos defendido que não há problemas novos na Educação desde a mudança de paradigma provocada por Ribeiro (1991), quando apresenta a reprovação como causa da evasão que, até então, era tida como a grande vilã da Educação brasileira. Após 30 anos da publicação, a reprovação continua a imperar como alternativa para os problemas registrados no campo da aprendizagem.

Por outro lado, as dificuldades causadas pela pandemia permitiram o surgimento de propostas metodológicas ou ferramentas tecnológicas que se dispunham a atenuar as dificuldades umas, enquanto outras alimentavam um grande "mercado de produtos e aparatos tecnológicos" para a Educação. Podemos escolher como bom exemplo, dentre tantos, o Guia Conectividade na Educação (GICE, 2021), organizado pelo Grupo Interinstitucional de Conectividade na Educação. Segundo o documento, o Guia de Conectividade foi "estruturado na forma de um manual com orientações sobre parâmetros de infraestrutura, distribuição de equipamentos e sinal nas escolas, alternativas de financiamento e modelos de contratação" (p. 2), e busca auxiliar gestores públicos nas diversas etapas de políticas públicas e gestão da conectividade das e nas escolas.

Como se pode perceber, houve um grande movimento de enfrentamento e de resistência envolvendo atores sociais dos mais diversos e, certamente, com abordagens próprias e com interesses dos mais variados. Para efeito didático, podemos categorizar esses atores sociais em uma "palheta de perfis" que vão desde a figura do ator social, indignado com as desigualdades que testemunhou, até aquele que está imerso nas arenas das lutas por superação das dificuldades com que convive cotidianamente. Gostaríamos de personificar esses dois perfis extremos com as figuras de Jean Ziegler e Viktor Frankl, certo que entre eles há uma gama de outros tantos perfis não descritos por conta do escopo sintético desse trabalho.

O sociólogo suíço Jean Ziegler (1934- ) viajou o mundo inteiro e conheceu de perto a vida de quem sofre de fome. Professor da Universidade de Genebra e da Sorbone, Ziegler ocupou vários cargos nas Nações Unidas como, por exemplo, o de Relator Especial para o Direito à Alimentação de 2000 a 2008 e membro do Comitê Consultivo do Conselho de Direitos Humanos da ONU de 2008 a 2012. Na introdução de seu livro Os Vivos e a Morte (ZIEGLER, 1977), ele conta que estava no Congo, em 1961, e que ao longo de 4 anos, as lutas internas e a fome mataram 2 milhões de uma população de 14 milhões. Ele descreve em detalhes pavorosos como as crianças negras, famintas e esquálidas, faziam o caminho proibido na direção do bairro dos brancos, onde não havia nenhuma carência. As crianças negras sequer podiam entrar nos espaços dos brancos. Nem a mendicância lhes era permitida. Descreve-as como frágeis, magras, fracas, 
sendo que as maiores arrastavam as menores. Elas são denominadas por ele como crianças-aranhas porque sequer conseguiam andar sobre as duas pernas ou crianças-sombras, que investiam na direção da barreira de soldados - os gurkhas, conhecidos mercenários servindo às Nações Unidas - contratados para isolar os brancos ricos da dura realidade da fome e da miséria africana. Ele escreve que, em grande e luxuoso hotel do setor internacional, muito bem protegido,

suave música escoava-se como chuva fina ao longo das brancas fachadas do hotel; no interior, sob os lustres, um embaixador qualquer oferecia uma recepção a um homem de negócios qualquer, de qualquer nação europeia. E o homem de negócios erguia a taça cheia de champanha, brindando em termos afetados a missão civilizadora do Ocidente no Congo. Preso à janela, eu via morrer as crianças. Os gurkhas, costas voltadas ao prédio, imperturbáveis, contentavam-se em agredi-los de formas variadas.

Ao final de seu texto, informa: "Jurei a mim mesmo que nunca mais, nem mesmo por acaso, estaria do lado dos carrascos [...] Lutaria para tornar-me, enfim, uma voz para os mártires sem voz". Assim o fez, tornando-se um importante personagem na luta internacional contra a fome, tendo diversos livros, alguns publicados em português. Por suas ações, Ziegler pode exemplificar aquele ator social que é tomado pela indignação com as desigualdades e promove intervenções efetivas a partir dos espaços de sua atuação. Em entrevista concedida quando esteve no Brasil, em 2019, (CHADE, 2019) ele diz que "A fome é feita pelas mãos do homem e pode ser eliminada pelos homens. Uma criança que morre de fome é assassinada".

No outro extremo podemos indicar Viktor Frankl (1905-1997), psiquiatra austríaco criador da Logoterapia e da Análise Existencial. Frankl ficou mundialmente conhecido quando descreveu sua experiência como sobrevivente de quatro campos de concentração nazistas, em obra intitulada Em Busca de Sentido: um psicólogo no campo de concentraçãa. Recebeu dezenas de títulos de doctor honoris causa, dentre eles o da Universidade de Brasília (FRANKL, 1991). Psiquiatra recolhido aos campos de concentração nazista por mais de 31 meses durante a $2^{\mathrm{a}}$ Grande Guerra, buscava encontrar alternativas para manter-se lúcido e vivo. Diz que, assim que chegou ao campo de concentração, elegeu para si três princípios: sobreviver, ajudar e tentar aprender que, aplicados aos diversos outros presos, permitiu que auxiliasse na sobrevivência deles frente às inenarráveis pressões do cotidiano. Após a guerra, passa a escrever e lega ao mundo uma grande e rica obra literária. Terá, então, a oportunidade de dizer que os que sobreviveram tinham ainda algo a fazer no seu futuro e tinham isso muito claro. Era o cientista 
com trabalhos importantes inacabados, era o avô que havia feito promessas a seu neto quando da separação pela guerra de extermínio etc. Pelo que viveu, realizou e legou, Frankl pode exemplificar os atores sociais imersos nas arenas das lutas por superação das dificuldades cotidianas. Encontramos esses atores sociais na figura de cada professor/gestor/pesquisador que busca superar as limitações educacionais já conhecidas e que foram agravadas pela pandemia.

A revista Ensaio hoje, como ao longo de sua história, tem sido o espaço de convergência das pesquisas, narrativas e experiências dessa ampla gama de atores sociais do universo multifacetado da Educação, cada um deles preocupado, à sua maneira, com os desafios da área e com contribuições singulares para o melhor entendimento e superação das questões educacionais contemporâneas. O número que hora apresentamos, imerso nas dificuldades agudas destes tempos estranhos a que estamos todos submetidos, demonstra bem essa pluralidade de temas, de autores, de instituições e de formas de ler e de descrever a realidade educacional em que estamos envolvidos. Nele encontraremos representantes das categorias simbolizadas desde Ziegler até Frankl.

O número 114 de Ensaio inicia com trabalho de Neves e Di Giorgi, ambos autores vinculados à Universidade do Oeste Paulista, apresentam o instigante e necessário trabalho sob o título De quem é a responsabilidade?: uma análise das perspectivas para a Lei de Responsabilidade Educacional, prevista no Plano Nacional de Educação. Suas reflexões encaminham-nos a posições importantes que realçam a qualidade da Educação como diretriz e indica como alternativa para LRE "articular elementos políticos, financeiros, administrativos, tecnológicos, organizacionais e pedagógicos para a promoção da Educação Básica pública com padrão mínimo de qualidade, afastando-se da ênfase punitiva como vetor de transformação."

O segundo artigo, intitulado Crowd-based Open Online Education as an alternative to the Covid-19 educational crisis, de autoria de Andrés Chiappe e de Alejandro Emilio Wills, ambos vinculados à Universidad de La Sabana, em Chía, Colombia, convida o leitor a refletir sobre o atual momento da educação no contexto da Covid-19 e à "Práticas Educacionais Abertas (OEP), a partir de uma perspectiva emergente, revisando suas conexões com a Educação a Distância e E-learning", abordagens que se tornaram comuns frente às limitações impostas pelo isolamento social.

$\mathrm{O}$ artigo seguinte nos chega do Distrito Federal. Jesus e Souza, da Universidade de Brasília, e Rêgo, do Centro Brasileiro de Pesquisa em Avaliação e Seleção e de Promoção de Eventos, apresentam o trabalho A questão da validade na avaliação 
educacional brasileira, no qual concluem que, no que tange às avaliações em larga escala no Brasil (Prova Brasil, Enem e Enade), "é necessário avançar tanto no entendimento do que é validade".

Os desafios da universidade pública pós-pandemia da Covid-19: O caso brasileiro, Cavalcanti e Guerra, ambas da Universidade Federal da Paraíba, apresentam amplo levantamento sobre as universidades brasileiras e suas atuações no período da Pandemia da Covid-19, propondo, ao final, práticas e ações que possam melhor contribuir para a superação dos desafios do período pós-pandemia.

Costa (Ministério da Defesa) e Canen (Universidade Federal do Rio de Janeiro) apresentam o resultado de seus estudos intitulado Internationalization of Higher Education Institutions: perceptions of scholars, em que tratam de tema em voga nas universidades brasileiras: a internacionalização. Eles apresentam caminhos e sugestões para a internacionalização das IES brasileiras, ressaltando "o fomento de pesquisadores internacionais e de sistemas de alocação de recursos para o financiamento de pesquisas".

Atentos aos fatores que contribuem para a eficiência escolar e utilizando metodologia da Análise Envoltória de Dados, Muniz e Andriola (Universidade Federal do Ceará), Muniz (Secretaria Municipal de Educação de Jijoca de Jericoacoara) e Thomaz (Universidade Estadual do Ceará), trazem no artigo Emprego do Data Envelopment Analysis (DEA) para estimar a eficiência escolar, tendo como foco a experiência exitosa de Sobral (CE), concluindo a importante contribuição da existência bibliotecas, de laboratórios de informática, de quadra de esportes e de salas para atendimento especial para a aprendizagem dos estudantes.

Considerando que os conflitos armados impactam os contextos escolares, Camargo e Sáez, ambos da Universidad de La Salle, em Bogotá, buscam conhecer os sentidos das práticas pedagógicas de professores de escolas normais localizadas em sete diferentes regiões afetadas pelo conflito armado interno colombiano. O trabalho Reconocimiento: una característica de las prácticas pedagógicas en relatos de maestros de escuelas normales superiores en contextos de conflicto interno en Colombia, certamente trará reflexões para que possamos, por analogia, melhor entendermos o que ocorre no universo escolar brasileiro que também tem experimentado esse tipo de conflito armado.

Esse número contempla também a área de formação de professores. Corrêa, do Instituto Superior de Educação Professor Aldo Muylaert, em Campos dos 
Goytacazes (RJ), apresenta pesquisa que analisou a trajetória formativa e profissional dos egressos do curso de Pedagogia daquela instituição de ensino. Em seu trabalho intitulado Egressos de um curso de Pedagogia: trajetórias formativas e profissionais ela conclui que a inserção profissional dos participantes da pesquisa na área da Educação alcança $75 \%$.

Nascimento e Andrade, da Universidade Federal de Pernambuco, tratam de importante tema para o acesso e permanência de estudante na escola: o transporte escolar. Na pesquisa School transportation program as means to improve public education in a minor rural town in northeastern brazil buscaram conhecer a opinião de professores e alunos de pequenos municípios rurais sobre o serviço ofertado e seus impactos. Dentre os pontos positivos indicados estão a pontualidade, a diminuição da evasão escolar e a melhoria do desempenho escolar.

É notório o crescimento na oferta de cursos de ensino a Distância ao longo dos últimos anos, fenômeno que pode ter se consolidado neste período de pandemia. Logo, são bem-vindo e necessários estudos que possam avaliar os processos de formulação, implantação, implementação e impacto desses cursos quando comparados aos cursos presenciais, cujas série histórica oferece bons números. Cortelazzo e Elisei, vinculados à Unicamp e ao Centro Paula Souza, SP, respectivamente, no trabalho Desempenho dos estudantes de cursos presenciais e a distância no ENADE em 2015, 2016 e 2017 apresentam resultados comparativos ente cursos $\mathrm{EaD}$ e presenciais, de instituições públicas e privadas, ao longo de três anos. As conclusões oferecidas permitem reflexõs importantes que podem indicar intervenções visando ao melhor atendimento dos estudantes que escolheram o EaD como caminho de formação.

Nas discussões atuais sobre temas relevantes que devem ser incorporados às práticas escolares, a resolução de problemas, as ações colaborativas, o pensamento crítico e outras abordagens da mesma família temática possuam grande relevância. No trabalho Resolução colaborativa de problemas: resultados brasileiros no pisa 2015, Leite e Miranda, da Universidade Federal de Rondônia, e Loye, da Universidade de Montreal, apresentam a resolução colaborativa de problemas (RCP) como uma competência ou habilidade crítica para ambientes educacionais e também laborais. Ao pesquisarem resultados colhidos no PISA 2015, os autores concluem que "os dados podem fornecer indicadores importantes sobre onde as capacitações, estudos e pesquisas podem focar em futuras reformas curriculares e políticas de melhoria da qualidade da Educação".

O estado de Santa Catarina foi pioneiro na implantação diretrizes de inclusão dos alunos com transtorno de déficit de atenção/hiperatividade (TDAH) e, por 
conta disso, Paes e Renk (PUC-PR) e Simão-Silva (Instituto para Pesquisa do Câncer, Guarapuava, PR), buscam estudar A beneficência em políticas de inclusão de alunos com o TDAH: um estudo de caso do decênio das diretrizes de educação especial em Santa Catarina e concluem que a "pesquisa aponta, primordialmente, para a necessidade de que a Educação Inclusiva se efetive de modo mais integral e mais humanitário, levando em consideração também outros princípios, como os de não discriminação, de não estigmatização, de igualdade, de justiça, de solidariedade, de cooperação, dentre outros...”.

Ao elencarmos os artigos que compõem o presente número de Ensaio indicamos a diversidade de temas, de abordagens, de áreas do conhecimento, de regiões e mesmo países, todos eles preocupados em oferecer reflexões que possam, de alguma forma, contribuir para a melhoria da Educação, por meio das Políticas Públicas e Avaliação. No seu conjunto, os artigos contemplam vários temas relevantes, além de contribuírem de forma objetiva para identificar fatores que afetam a equidade educacional em vários níveis ou que solapam os processos formativos ou de gestão que, por fim, reduzem a efetividade dos resultados finais da Educação e do Ensino.

Estes são tempos difíceis, mas já é possível vislumbrar a superação das dificuldades impostas pela Covid-19 e seremos todos chamados, cada uma à sua maneira, a contribuir com esse novo momento que surgirá em breve. Serão contribuições singulares que, no conjunto, contribuirão para a superação dos tempos de incertezas.

Podemos afirmar que Ensaio contribui para esse tão esperado momento. 


\section{Referências}

BARROS, R. P., et al. Perda de aprendizagem na pandemia. São Paulo: Instituto Unibanco; Insper. 2021.

CHADE, J. A esperança está na sociedade civil planetária, segundo Jean Ziegler. Época, Rio de Janeiro, n. 1091, 30 maio 2019 [acesso em $16 \mathrm{dez}$ 2021]. Disponivel em https://oglobo.globo.com/epoca/a-esperanca-esta-nasociedade-civil-planetaria-segundo-jean-ziegler-23704511

FRANKL, V. E. Em busca de sentido: um psicólogo no campo de concentração. Petrópolis: Vozes, 1991.

GOMES, C. A. et al. Education during and after the pandemics. Ensaio: Avaliação e Políticas Públicas em Educação, Rio de Janeiro, v. 29, n. 112, jul.-set. 2021. https://doi.org/10.1590/S0104-40362021002903296

GRUPO INTERINSTITUCIONAL DE CONECTIVIDADE NA EDUCAÇÃO - GICE. Guia conectividade na educação: passo a passo para a contectividade das escolas públicas brasileiras. São Paulo: GICE, 2021 [acesso em 16 dez 2021]. Disponível em: https://nic.br/media/docs/ publicacoes/13/20210916130704/guia-conectividade-na-educacao.pdf

REDE BRASILEIRA DE PESQUISA EM SOBERANIA E SEGURANÇA ALIMENTAR E NUTRICIONAL - REDE PENSSAN . Insegurança alimentar e Covid-19 no Brasil. Rio de Janeiro: Escola Nacional de Saúde Pública Sergio Arouca, 13 abr. 2021 [acesso em 16 dez 2021]. Disponível em: https://dssbr.ensp.fiocruz.br/inseguranca-alimentar-e-covid-19-no-brasil/

RIBEIRO, S. C. A pedagogia da repetência. Estudos Avançados, São Paulo, v. 12, n. 5, p. 7-21, maio/ago.1991. https://doi.org/10.1590/S0103-40141991000200002

\section{UNITED NATIONS EDUCATIONAL, SCIENTIFIC AND CULTURAL} ORGANIZATION - UNESCO. Impacto da Covid-19 na educação. Washington, DC, 2021. Disponível em: <https://pt.unesco.org/covid19/ educationresponse>. Acesso em: 16 dez. 2021.

WORLD BANK. O estado da crise global da educação um caminho para a recuperação. Washington, DC: World Bank, 2021[acesso em 16 dez 2021]. Disponível em: https://documents.worldbank.org/en/publication/documentsreports/documentdetail/383711638854600820/executive-summary

ZIEGLER, J. Os vivos e a morte. Rio de Janeiro: Zahar, 1977. 


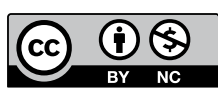

\section{Informações sobre o autor}

Alvaro Chrispino: Doutor em Educação pela Universidade Federal do Rio de Janeiro. Professor Titular do Centro Federal de Educação Tecnológica Celso Suckow da Fonseca, RJ. Bolsista de Produtividade do Conselho Nacional de Desenvolvimento Científico e Tecnológico-CNPq, área de Educação. Contato: alvaro.chrispino@gmail.com

iD https://orcid.org/0000-0001-9914-3471 